\title{
QUANTITATIVE AND QUALITATIVE ANALYSIS OF WALKABILITY OF INDIAN STREET: A CASE OF LUCKNOW
}

\author{
Ar. Divya Pandey \\ Faculty of Architecture, Dr. APJ Abdul Kalam University, Lucknow
}

\begin{abstract}
Walkability became one of the important aspects of new urbanism. Increase in the numbers of the vehicle on the road creating a havoc situation for society. It is also polluting our environment. Enhancing walkability wit in a city or in a neighborhood became a challenge for the city developer. There is no proper way established by which we can identified the street those need improvement in the street and we have also not established the parameter by which walkability can be improved in an area. In this paper parameter has been identified which can help in improving the walkability of Indian street. Both qualitative and quantitative parameters have been listed down and all are converted into numerical value so we can quantify the quality of walkability in an area for the calculation of the walkability in existing scenario. By the help of this method we can improve walkability of any area.
\end{abstract}

\section{KEYWORDS}

Walkability, Qualitative and Quantitative parameters

\section{INTRODUCTION}

Walkability can be defined as "the extend to which the built environment is friendly to the presence of people living, shopping, visiting, enjoyed or spending time in the area."- ABLEY STEPHEN "Walkability is a quantitative and qualitative measurement of how inviting or uninviting an area is to pedestrians. Walking matters more and more to towns and cities as the connection between walking and socially vibrant neighborhoods is becoming clearer. Built environments that promote and facilitate walking - to stores, work, school and amenities - are better places to live, have higher real estate values, promote healthier lifestyles and have higher levels of social cohesion". - JAN GEHL

In the twenty first century cities are turning into a place full with chaos, unhealthy environment, full of noise and are becoming in-habitable. With the population demand and the rising pressure our natural resources are diminishing day by day. So, for our future generations creating our cities into a habitable place, sustainable development should be the main concern of our city planners and designers. Sustainability can only be achieved when there is an accurate balance between Social, Economics and Environment. Thus, bearable, equitable and viable scenario can be created.

For a sustainable development in a city, many tools now days have been experimented and researched. "Walkability" is one of the tools that has been emerging and can be helpful in DOI:10.5121/civej.2016.3302 
creating sustainable cities. Initially our Indian cities were walk-able, but due to the introduction of the mechanized transportation, roads were developed more for the automobiles rather than for the pedestrian. In city development plan, no thoughts were being given to pedestrian network. Slowly and steadily cities became eccentric towards mechanized transport.

The major effect of automobile was the urban sprawl. With the pressure of the increasing population, city limits are increasing day by day. Mixed use development is no more exercised. The other effect of automobile was that now for the vehicles, broad roads were constructed. Initially city fabrics were demolished to develop roads and today roads have become a governing factor in formation of the fabric.

Due to increase in the city limits people tend to take vehicle for transportation because now we could reach anywhere in very minimal time and walking is no longer a feasible option today. Now people have to roam around in different sectors for day to day activities and the roads are so designed which make walking a difficult task. All these effects directly influenced the pedestrian movement.

All these issues affect the social, economical and environmental health of the cities. Roads took all the spaces where people could interact with each other. The Social interaction spaces are no more developed and are no more a concern for the city developer. To develop the roads or even to widen the road always green trees are cut down which directly affect the environment of the area. Roads with vehicle movement never help in the business along side when we compare a street with pedestrian movement; it always helps to generate business for vendors, also every year lot of money is issued for the construction of the road, but on the other hand by creating space for the pedestrian to walk will also help in people to interact, no more trees will be cut down because pedestrian doesn't need straight line pathway thereby saving many trees to cut down and pedestrian pathway always helps in generating income for the vendors.

\section{PARAMETERS}

In urban design literature we can find that there are some urban design qualities which affect the walkability. These qualities can be majorly distributed in 2 categories first is physical features and second is non-physical features which can be termed as perceptual qualities. Under physical feature building typology, land use, dwelling density, retail area, urban infrastructure like sidewalk width, street width, traffic volumes, tree canopy, weather, etc. In perceptual qualities enclosure, imagine ability, transparency, complexity, human scale, legibility, etc comes under this category. But between all these qualities there are some qualities which will be appropriate for Indian scenario and some will be not fit for Indian cities for example transparency - As we know that transparency is a material condition that is pervious to light and/ or air, an inherent quality of substance as in a glass wall. A classic example we found in the urban design literature is a shopping street with display window that invites passers-by to look in and then come to shop but in Indian traditional market items were directly display on the streets because it is an Indian shopping habit to touch the things and if there is fruit or any eatables are selling then they smell it or taste it, even if there is shoe shop then they will directly put there one shoe from the pair on the street display in front of the shop either they are already displaying shoes in their glass display in the frontage of the shop. In residential area nobody like transparency in their wall, there will be a hierarchy of spaces in the opening area But transparency cannot be seen in Indian scenario. So, there will be some urban design qualities which only appropriate for the Indian context. These all qualities can be explored.

So the parameters which are affecting the walkability are: 


\subsection{Enclosure}

An enclosure is estimate by the edges or boundaries. An indoor space has floors, ceiling, walls as the boundaries. Same in the case of outdoor space road and pathway are the floor of space the facade of building is walls of the space trees canopy or sky is the ceiling of the outdoor space. In indoor space the enclosed space is $100 \%$. Alexander et al (1977, pp 489-491) stated that the total width of the street, building to building should not exceed the building height. Allan Jacobs (1993) suggest that the proportion of the building height to street width should be least 1:2. Other designer recommended proportion as high as 3:2 and as low as 1:6 for sense of enclosure. As a general rule tighter the ratio tighter the enclosure.

2.1.1 1:4 - an object becomes part of the surrounding, loss of enclosure, just an edge.

2.1.2 1:3- - an object is part of surrounding but still dominates it, minimum enclosure, prominent objects beyond space are perceived as much as space.

2.1.3 1:2- an object is perceived "as a little world in itself", threshold of distraction, lower limit for creating enclosure.

2.1.4 1:1- produces the best distance from which the details can be observed in relation to whole. Full enclosure since building is considerably higher than the upper limit of the frontal view.

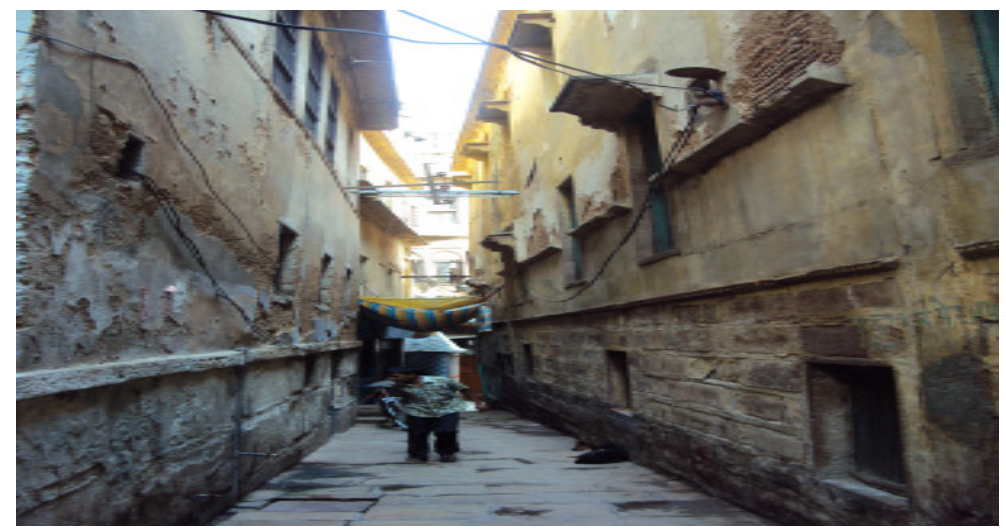

\subsection{Human Scale}

Figure 1. Street of Varanasi

The relationship between the environment and the human body size is known as human scale. Any element can be in a human scale when from a distance the wholeness of an object as well as its smallest recognizable part can be seen at a one glance.

\subsection{1 $0-1.5$ feet- intimate distance.}

2.2.2 70 feet- loud voice can be just heard

2.2.3 40 feet - distinguishable face

2.2.4 12 feet-40 feet - public distance

2.2.5 4.5-12 feet- social distance 


\subsection{Climatic Aspect}

Provision of climatic comfort for pedestrian network is very essential in India, where the temperature varies from 45 degree in summers and 2 degree in winters. The period of summers is of 7-8 months and winter stays only for 3-4 months.

\subsection{Complexity}

Amos Rapport (1990) "describe the essential property is related to the number noticeable difference to which a viewer is exposed per unit time". Human being is in comfort at certain level when it is in most usable. Too little noticeable things can encourage the neediness and people will get bore by that kind of system. But too much information per unit time will also create chaos to the sensory system. At the speed of $5 \mathrm{~km} / \mathrm{h}$ people can absorb more information rather than the when person was driving by car at the $40 \mathrm{~km} / \mathrm{h}$. Complexity is influence by these factors:

2.4.1 Number of element present in the viewer's view

2.4.2 Elements variety - either they are very similar or dissimilar

2.4.3 Prediction of the element - either they are creating surprise or novelty.

2.4.4 Composition of the element- either they are orderly placed or very random.

\subsection{Linkages}

Linkage theory tries to organize a system of relations, or a network, that establishes an arrangement for ordering spaces. The significant aspect is to create logical link between the discrete things

\subsubsection{Street linking to some major road.}

2.5.2 Street linking to above with public transport route

2.5.3 Street linking to above with commercial area present in between

2.5.4 Street linking to above with presence of institutional area and recreational area.

2.5.5 Street linking above with presence of informal and religious activity.

\subsection{Mixed Use}

Jane Jacob says "Intricate mingling of different uses in cities are not a form of chaos, On the contrary, they represent a complex and highly developed form of order." Mixed use development increase the possibility of fulfilling all the need at walkable distance as the use of the surrounding is mixed.

\subsubsection{Only residential}

2.6.2 Residential with commercial

2.6.3 Above with institutional

2.6.4 Above with recreational

2.6.5 Above with informal activity 


\subsection{Provision Of Pathway}

Presence of the physical infrastructure which is important for creating walkable spaces helps in increasing wakability of the area pathways are one on them.

\subsubsection{No area to walk}

2.7.2 Shoulder space is there but pavement wad not made.

2.7.3 Pavement was made but not maintained and also not wide enough to walk on.

2.7.4 $1.5 \mathrm{~m}$ wide pavement is their but with some obstruction.

2.7.5 $1.5 \mathrm{~m}$ wide pathway with well maintained and tiled pavement.

\subsection{Crossing Safety}

Movement of the vehicle on the road works as a barrier for both pedestrian networks along the sides of the road. We need crossing safety for the pedestrian to enhance the network of the pedestrian.

2.8.1 Average distance of controlled crossings is greater than $500 \mathrm{~m}$ and average speed is high

2.8.2 Average distance of controlled crossings is between $500 \mathrm{~m}-300 \mathrm{~m}$ and average speed is around 40kmph

2.8.3 Average distance of controlled crossings is between $200 \mathrm{~m}-300$ mand average speed is 20 $40 \mathrm{kmph}$

2.8.4 Average distance of controlled crossings is between $100 \mathrm{~m}-200$ mand average speed is 20 $40 \mathrm{kmph}$

2.8.5 There is no need of controlled crossings as pedestrians are safe to cross wherever they like and vehicles and pedestrian co-exist.

\subsection{Perception Of Crime}

People avoid walking on those streets where they do not feel secure. To increase the walkability in the area we need more secure streets.

2.9.1 Presence of light pole along the light

2.9.2 Presence of light pole with regular basis maintenance of the lights.

2.9.3 Presence of above with commercial area.

2.9.4 Presence of above with less setback houses.

2.9.5 Presence of above with some religious building or police chowky.

\subsection{Maintenance and Cleanliness Of Walkable Paths.}

Maintenance of the physical infrastructure of the streets which are essential for walkable streets and the cleanliness of that area is very important to motivate people to walk.

2.9.6 Presence of garbage collection system in the neighbourhood.

2.9.7 Presence of above with provision sweeping of roads.

2.9.8 Presence of above on daily basis. 
2.9.9 Presence of above with provision of bins along the road.

2.9.10 Presence of above with new technological approach used for cleanliness and maintenance.

\subsection{Existence and Quality Of Facilities For Blinds and Disable}

Specially challenged people are also part of our society but when it comes to development we never take them into consideration and design for the major one, which is very wrong practice.

2.10.1 No infrastructure for physically challenged people is available.

2.10.2 Limited infrastructure for physically challenged people is available, but is not in usable condition

2.10.3 Infrastructure for physically challenged people is in place but in poor condition and not rightly located

2.10.4 Infrastructure for disabled persons is present, in good condition, but poorly located

2.10.5 Infrastructure for disabled persons is present, in good condition, and rightly located

\subsection{Amenities}

Presence of the basic amenities along the roads and pathways helps in motivating people to walk to commute from one place to another.

2.11.1 Provision of toilets

2.11.2 Availability of drinking water

2.11.3 Provision of above with sitting space

2.11.4 Provision of above with proper lighting system

2.11.5 Provision of above with presence of shading which protects from sun and rains.

\subsection{Obstruction}

Any kind of hurdle present of the pathway makes people to avoid walking on that area, so any kind of obstruction should be removed from the pathway.

\subsubsection{Obstruction from transformer}

2.12.2 Obstruction from construction material with above

2.12.3 Obstruction from garbage with above

2.12.4 Obstruction from above with extended shopping area

2.12.5 Obstruction from above with extended garden area.

\subsection{Policy Support}

Government support through different kind of policy in terms of safety of the pedestrian and the infrastructure for the pedestrian network will help in creating walkable streets.

2.13.1 funding and resource devoted to pedestrian

2.13.2 Presence of relevant urban design guideline with above.

2.13.3 Existence and enforcement of relevant pedestrian safety laws and regulations with above.

2.13.4 Degree of public outreach for pedestrian safety laws and regulation with above. 


\section{A CASE OF LUCKNOW}

The case study will look at walkability as a new layer superimposed on the existing city fabric connecting neighborhood. In this study I have tried to analyze both the qualitative and quantitative parameters which became urban design tools and principles that priorities pedestrian and non motorized transport instead of motor vehicle in a neighborhood.

\section{Criteria For Site Selection}

- The site should be a typical Indian situation where city level activities grow in neighbourhood attracting huge crowd resulting in chaos and conflict between pedestrian and other mode of transportation.

- It should be well connected with city through various links of public transportation like bus and auto, so that they could become potential carrier of people.

- The typology of fabric should be contemporary in nature and area should be residential in land use.

- The site should be a multi use zone in terms of land use with residential being an integral part so that the place should have active usage all throughout the day and also various type of usage as all land use requires different type of support use.

- The zone should be a mix of various character areas having different image so that an interesting design thesis could be attempted.

\section{SITE INTRODUCTION}

The site chosen for the demonstration is located in northern part of Lucknow containing area between Ring road and Faizabad road; Indiranagar - A block, B block, C block, D block, sector 22, 24, 20, 18 and last sector 16. The area has tremendous potential in term of pedestrian development as these are area of high footfall and huge problem like parking, conflict zones between pedestrian and vehicles and every area is unique in itself.

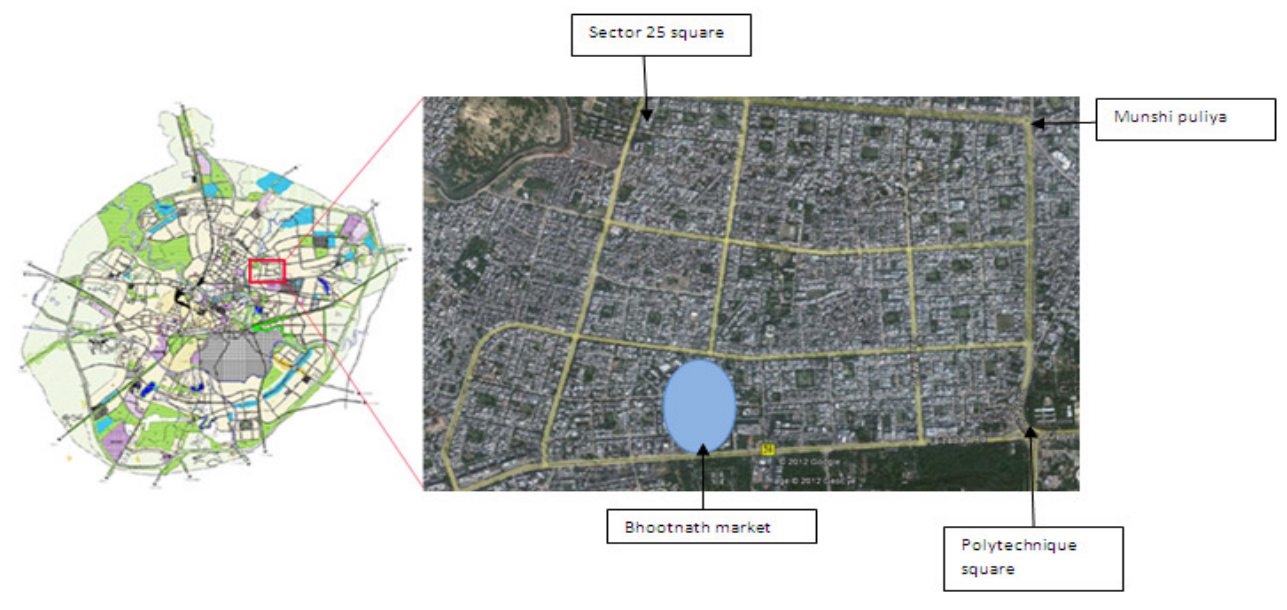

Figure 2. Satellite image of Indiranagar 


\section{ANALYSIS OF THE AREA}

For the better understanding of the area a survey was conducted by which different layer of the urban form was developed. By this exercise we are able to understand the existing scenario of the neighborhood.

\subsection{Morphological Analysis}

Firstly we try to understand morphology of the area. We try to visualize the existing scenario of massing in the area. For we try to generate figure ground map, land use map, building typology etc. on which intensity, texture, grain was studied.

\subsubsection{Figure Ground Mapping}

Area was developed in grid iron pattern. Most of the part of the area is already built. The open space present in the area is very fragmented and is in smaller in size.

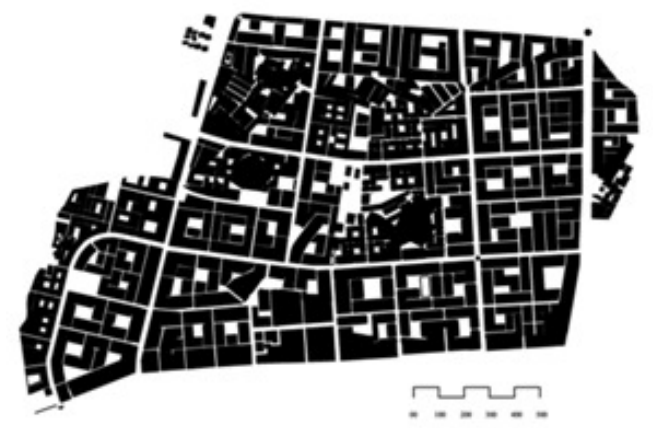

Figure 3. Figure ground map

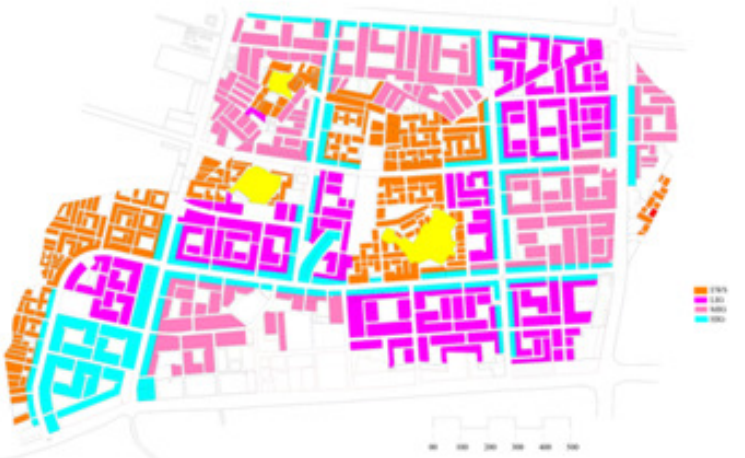

Figure 4. Housing typology map

\subsubsection{Building Typology}

In this area there are major four type of residences are there, first is H.I.G whose plot area is approx. 1800 sqft. They are usually semi detached in nature and the front setback is approx $4.5 \mathrm{~m}$ apart from in A-block most of the H.I.G. is on the arterial road which are mostly 18 meter Wide. The streets with H.I.G housing have very less activity and most of the time they are abounded. This type of street character can be seen in the sector with M.I.G housing type. The third typology of residence is L.I.G which is approx 1200sqft in area. The setback in this typology is one meter and the feeder road in front of this housing is approx 6 to 9 meter wide. These roads are more humanized in nature. These streets are very active in nature. The enclosure and human scale of these streets are much more appropriate than the street section on the H.I.G. The last typology is E.W.S housing, whose area of dwelling was approx $900 \mathrm{sq} \mathrm{ft}$. There is no restriction in the setback and the feeder road which is provided in this sector is $3 \mathrm{~m}$. The enclosure, human scale, degree of interaction on the road with the informal activity performed on the street are most humanized in nature comparing to other sector of Indiranagar. 


\subsubsection{Landuse}

This area was developed to reduce the gap between the demand and supply of the housing stock, so we can see in the land use map that $80 \%$ of the building is under residential land use. Apart from residential, few schools had been provided for approximately for one sector under institutional land use. After that some commercial streets had been developed due the need of the people.

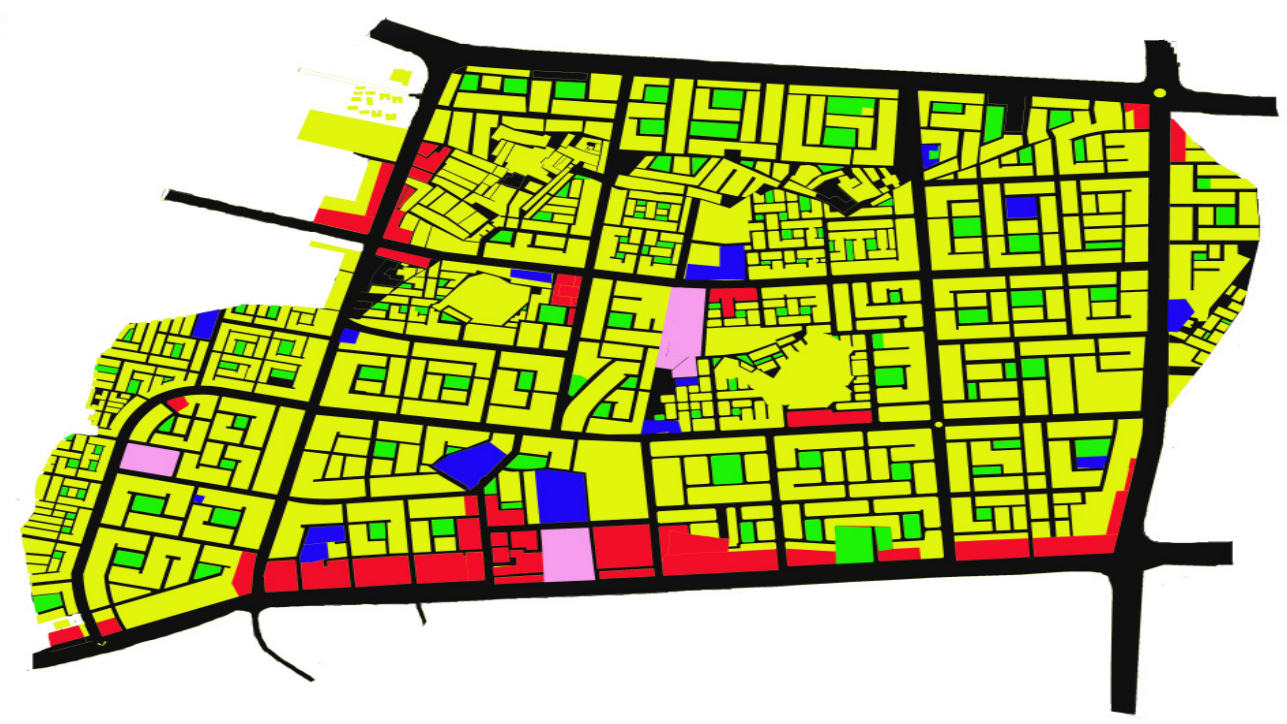

Figure 5. Land Use Map

\subsubsection{Movement Pattern}

There are 2 main arterial roads around the neighbourhood one is ring road and second is Faizabad road, which are becoming edges of the site and separating it from other district. Then there are sub-arterial road which are fragmenting whole area into different sectors then there are collector road and local road. Major pedestrian movement on the site is on the route where public transport is moving after that route which is approaching to the public transport route where people are walking. Major traffic jam was on Munshipulia square, polytechnic square and on sector 25 junction. Problem of congestion was there on happening on Bhootnath temple road also because of the commercial activity. The right of way of these street are varies from 18 meters to 3 meters. There is no separate pathway is provided for the pedestrian. Whole right of way is dedicated to either black tar and remaining is left for the green belt. There is no infrastructure for the pedestrian in whole area. The major pedestrian footfalls are in the Bhootnath market area but that area is also open for all kind of vehicles. There is no restriction in entry of this precinct. Even in whole neighbourhood there is no area which restricts any kind of vehicular entry. On some street people have constructed unauthorised gate for the security which also restrict the pedestrian entries. These kind of use should be banned. Although development authority have demolished 
few gates, but many gates are still there in the neighbourhood which became very problematic for pedestrian movement.

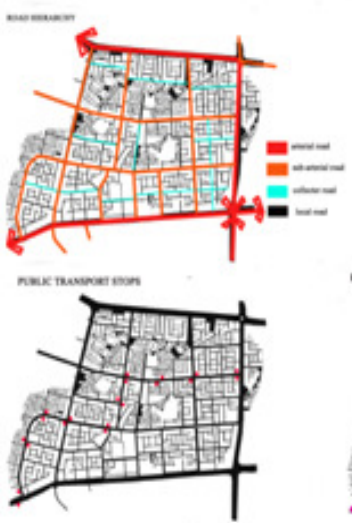

Figure 6. Movement pattem
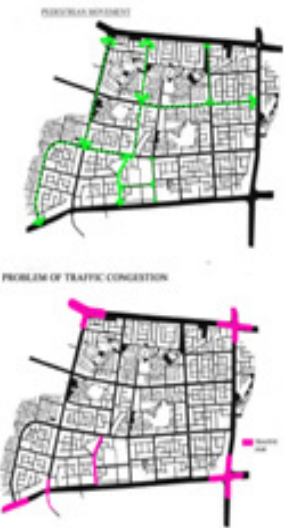

\section{,}

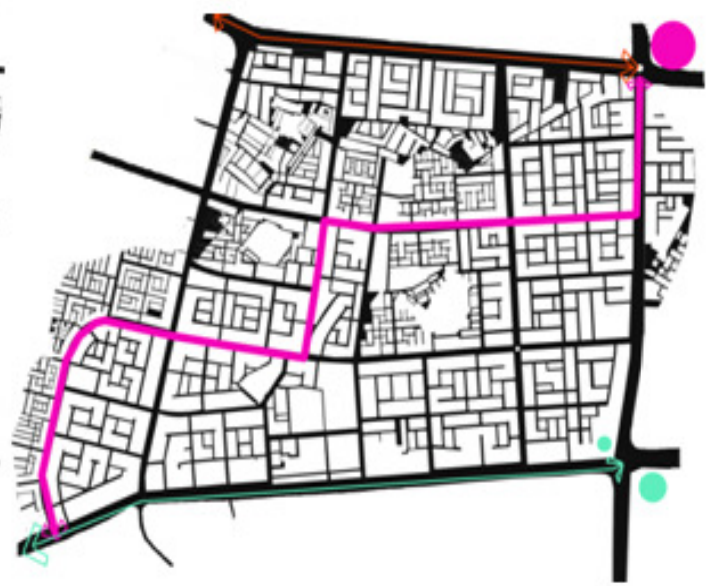

Figure 7. Movement Pattem

\subsubsection{Public Transport}

The main public transportation route crosses the area diagonally. On this main route share auto, busses and tempo use to ride. Apart from that on arterial road which is making edge, busses and tempo use to ride, which is connecting other part of the city to Indiranagar.

\subsubsection{Activity}

Most of the activities in the site are concentrated on various intersections of the roads. Almost most active node are combined of commercial, religious and informal activity

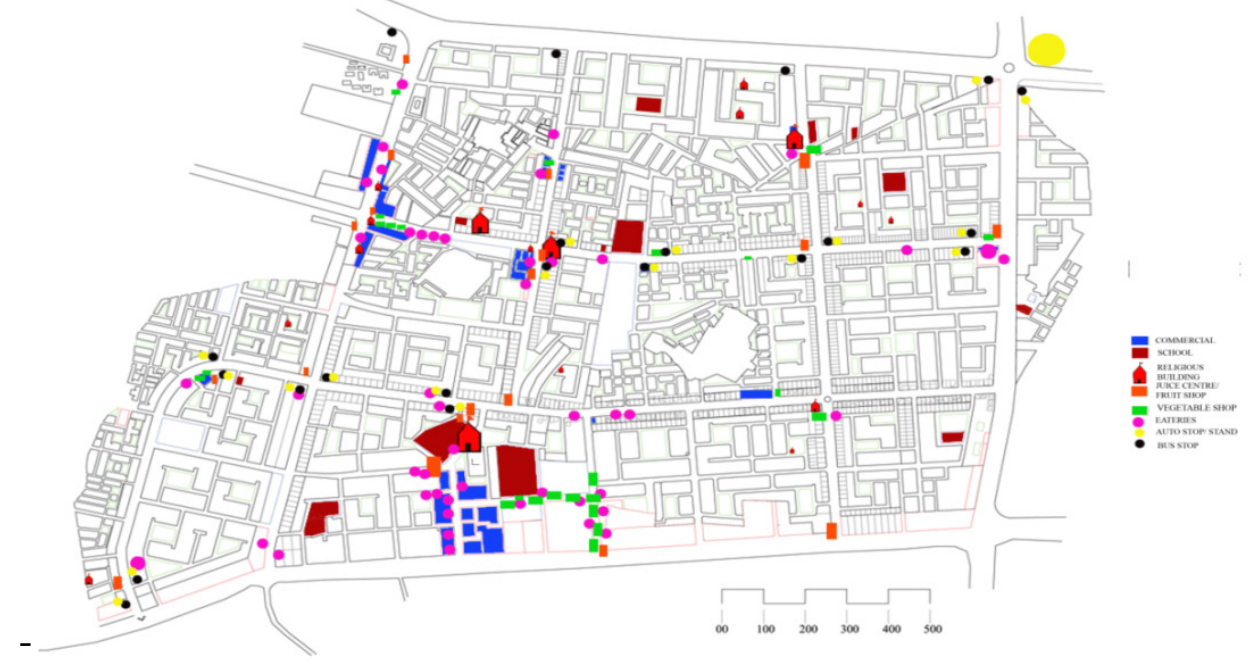

Figure 8. Activity Mapping 


\section{INFERENCES OF THE ANALYSIS}

After this analysis, four different kind of areas can be identified, which has different characteristics. These four different areas can be treated as a different project, these individual project need different kind of approach. Combination of all these project or enhancement of this entire project will help into converting this neighborhood into more walkable area. So the four different kind of area in indiranagar are-

- Street which has high foot fall

- Street which has low footfall

- Area within a district

- Bhootnath market area.

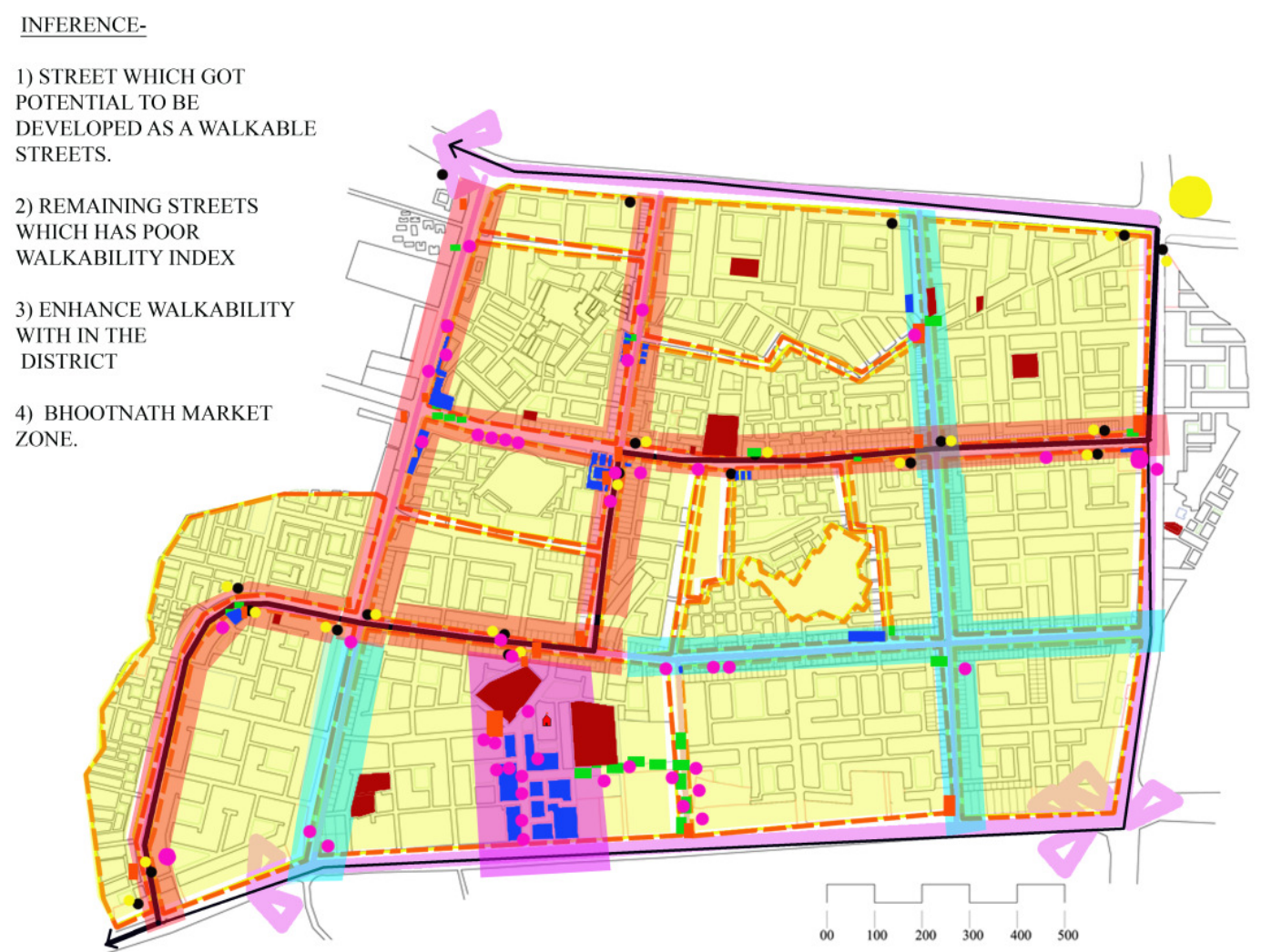

Figure 9. Area delineation map for project

To prove that above statement and to analyze the walkability of the entire street, all the parameters are assigned marked according to the presence of infrastructure and their status. This making system is done on all the street present in the neighborhood. And according to the marks their present scenario can be judged. For this a matrix can be made and each and every street can be evaluated. So a survey was conducted of each street present in the neighborhood, and marking was done as explained in the above section of the paper. 


\section{Sample sheet used for survey}

\begin{tabular}{|c|c|c|c|c|}
\hline PARAMETERS & $\begin{array}{l}\text { ASSISNED } \\
\text { MARKS }\end{array}$ & $\begin{array}{c}\text { STREET- } \\
1\end{array}$ & $\begin{array}{l}\text { STREET- } \\
2\end{array}$ & $\begin{array}{l}\text { STREET- } \\
3\end{array}$ \\
\hline \multicolumn{5}{|l|}{ A) Provision of pathway- } \\
\hline 1) No area to walk & 1 & & & \\
\hline 2) Shoulder space is there but pavement wad not made. & 2 & & & \\
\hline $\begin{array}{l}\text { 3) Pavement was made but not maintained and also not wide } \\
\text { enough to walk on. }\end{array}$ & 3 & & & \\
\hline 4) $1.5 \mathrm{~m}$ wide pavement is their but with some obstruction. & 4 & & & \\
\hline $\begin{array}{l}\text { 5) } 1.5 \mathrm{~m} \text { wide pathway with well maintained and tiled } \\
\text { pavement. }\end{array}$ & 5 & & & \\
\hline \multicolumn{5}{|l|}{ B) Crossing safety- } \\
\hline $\begin{array}{l}\text { 1) Average distance of controlled crossings is greater than } 500 \mathrm{~m} \\
\text { and average speed is high }\end{array}$ & 1 & & & \\
\hline $\begin{array}{l}\text { 2) Average distance of controlled crossings is between } 500 \mathrm{~m}-300 \mathrm{~m} \\
\text { and average speed is around } 40 \mathrm{kmph}\end{array}$ & 2 & & & \\
\hline $\begin{array}{l}\text { 3) Average distance of controlled crossings is between } 200 \mathrm{~m}-300 \mathrm{~m} \\
\text { and average speed is } 20-40 \mathrm{kmph}\end{array}$ & 3 & & & \\
\hline $\begin{array}{l}\text { 4) Average distance of controlled crossings is between } 100 \mathrm{~m}-200 \mathrm{~m} \\
\text { and average speedis } 20-40 \mathrm{kmph}\end{array}$ & 4 & & & \\
\hline $\begin{array}{l}\text { 5) There is no need of controlled crossings as pedestrians are safe to } \\
\text { cross wherever they like and vehicles and pedestrian co-exist. }\end{array}$ & 5 & & & \\
\hline
\end{tabular}

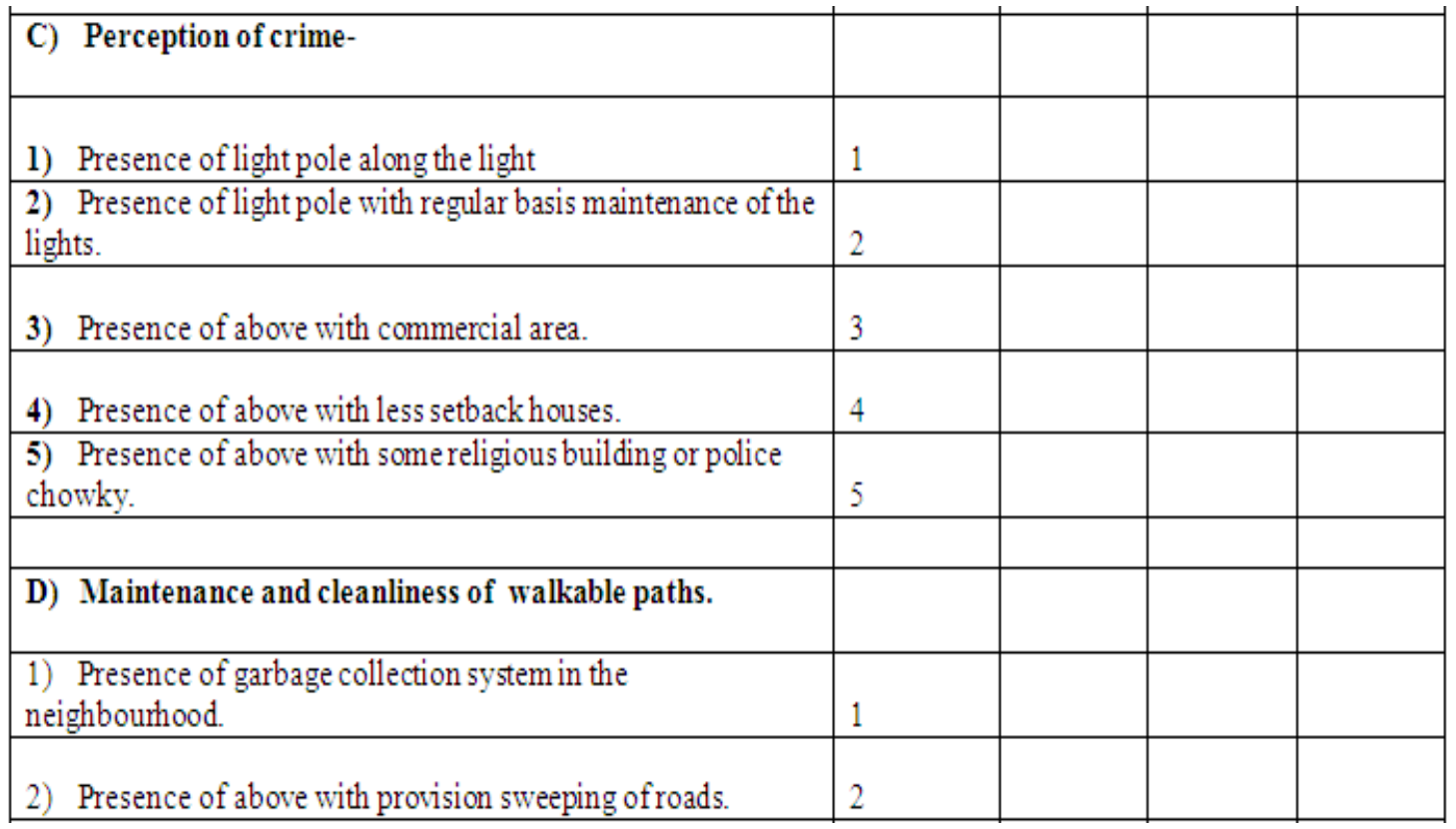




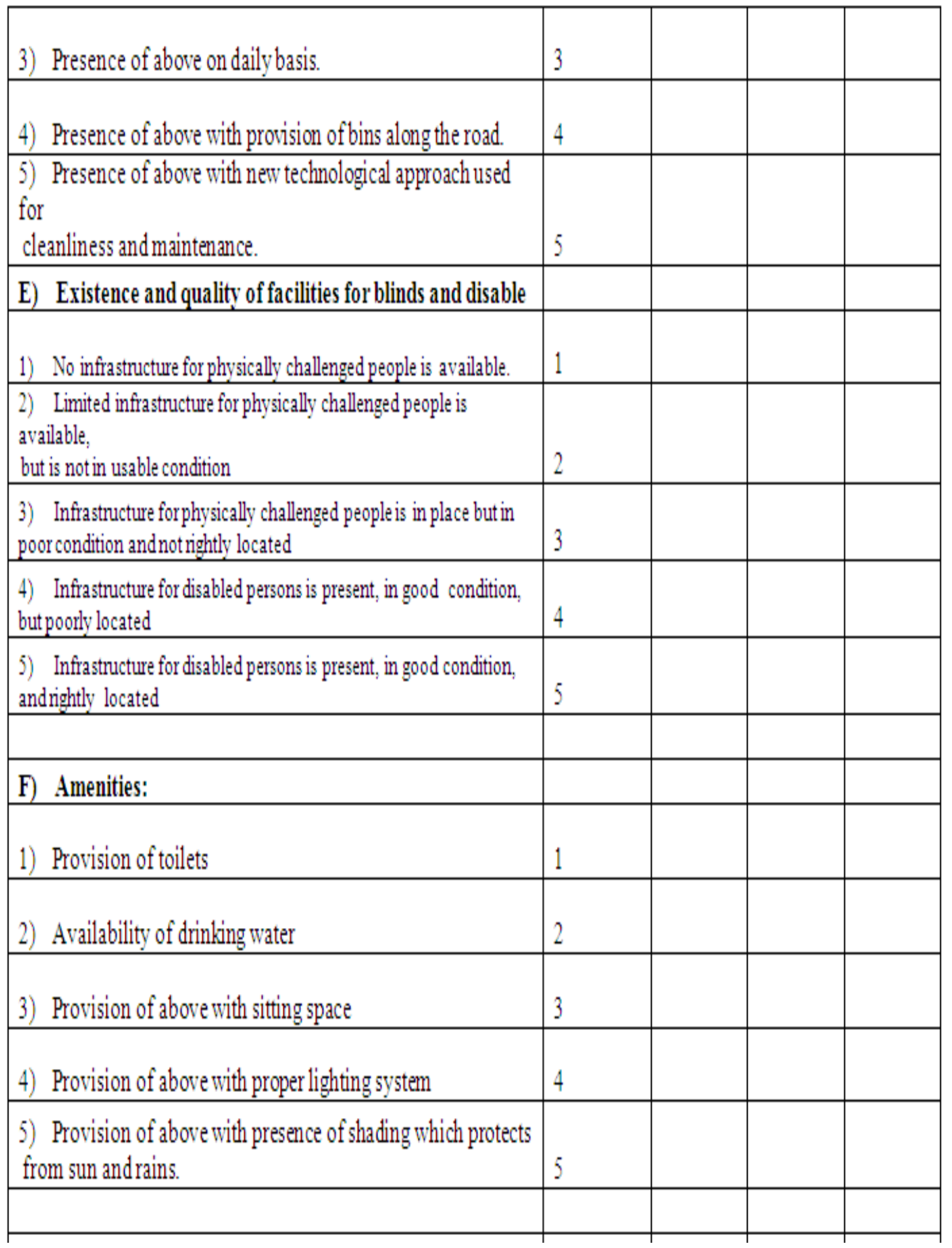




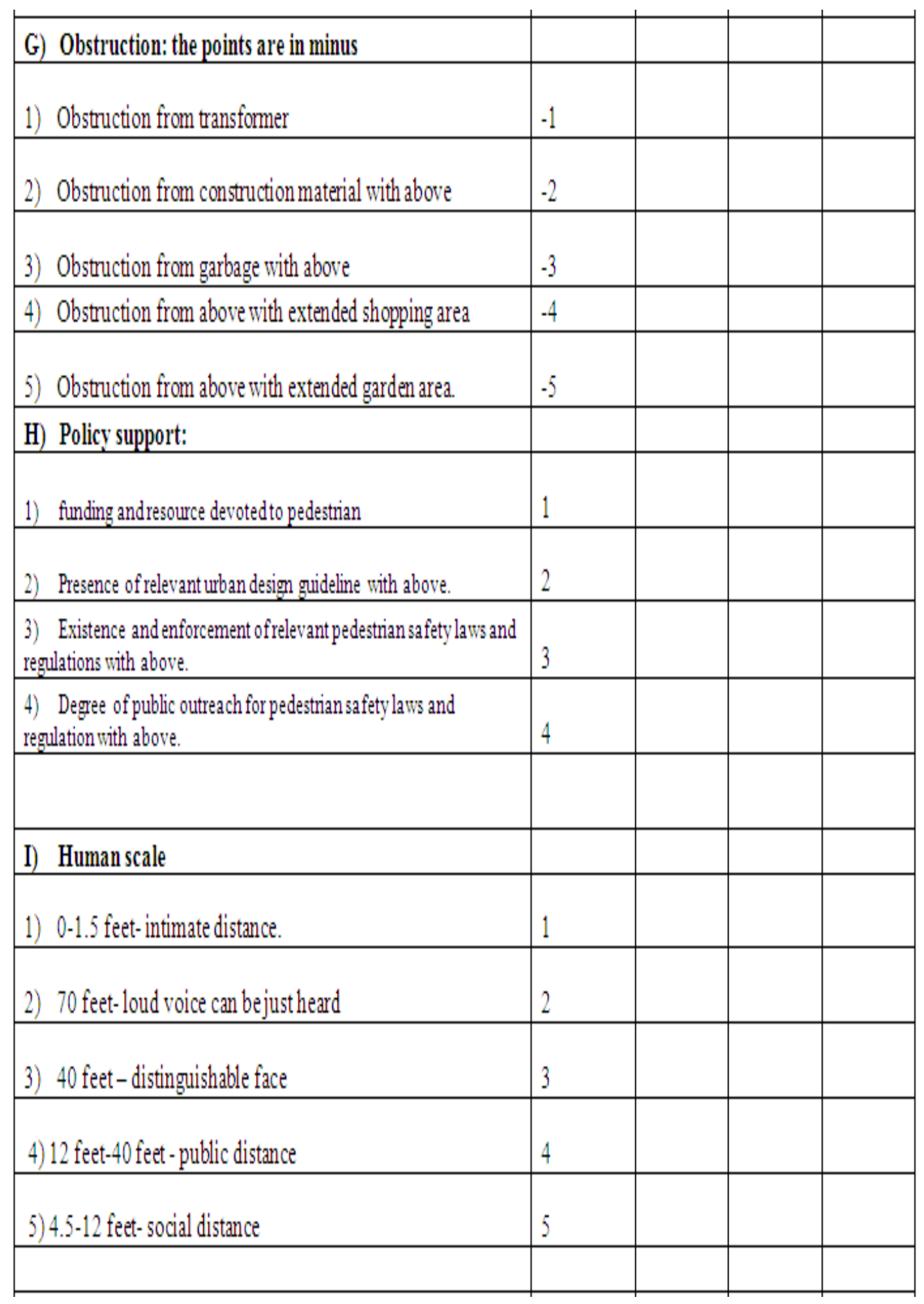


Civil Engineering and Urban Planning: An International Journal (CiVEJ) Vol.3, No.3, September 2016

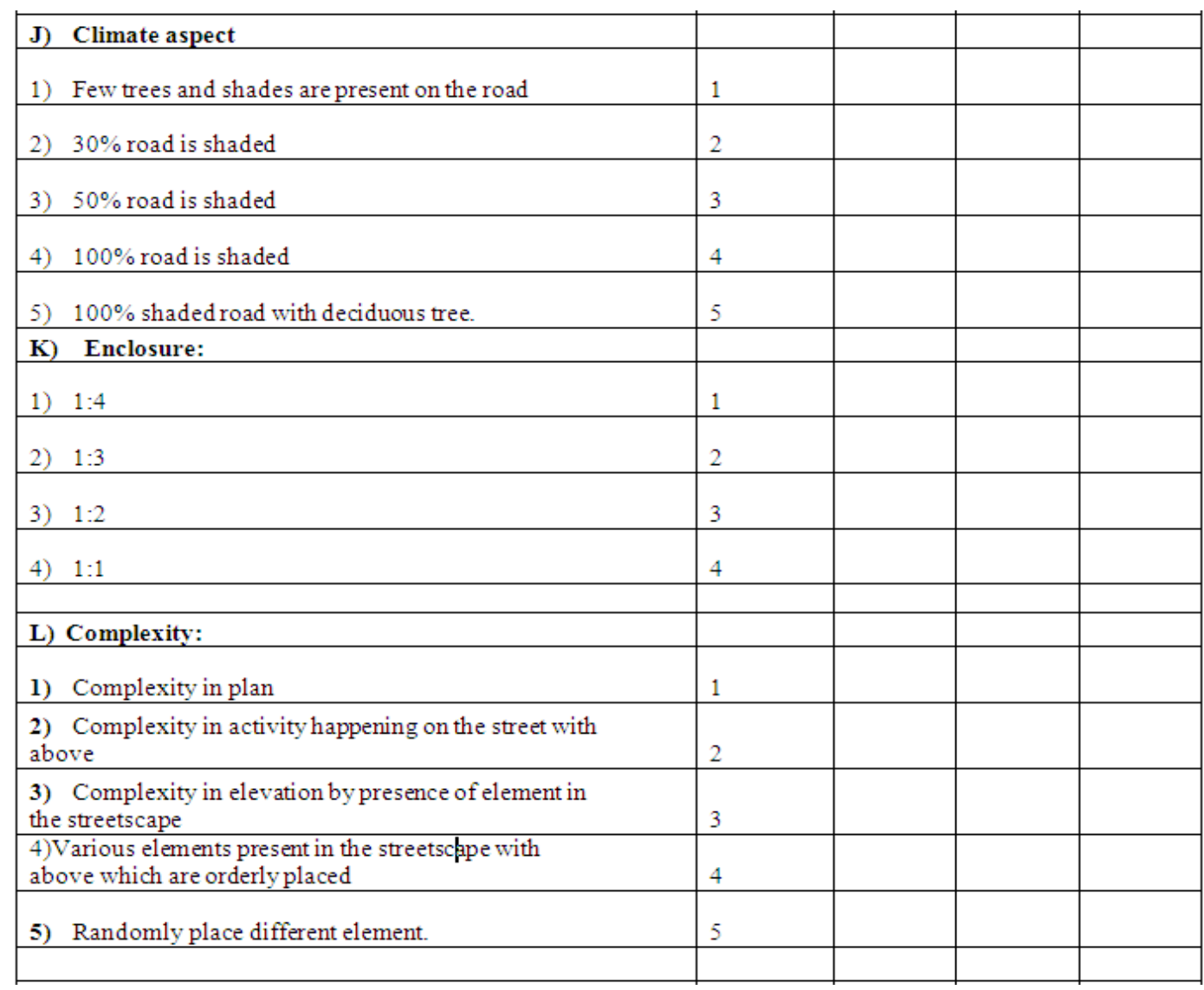

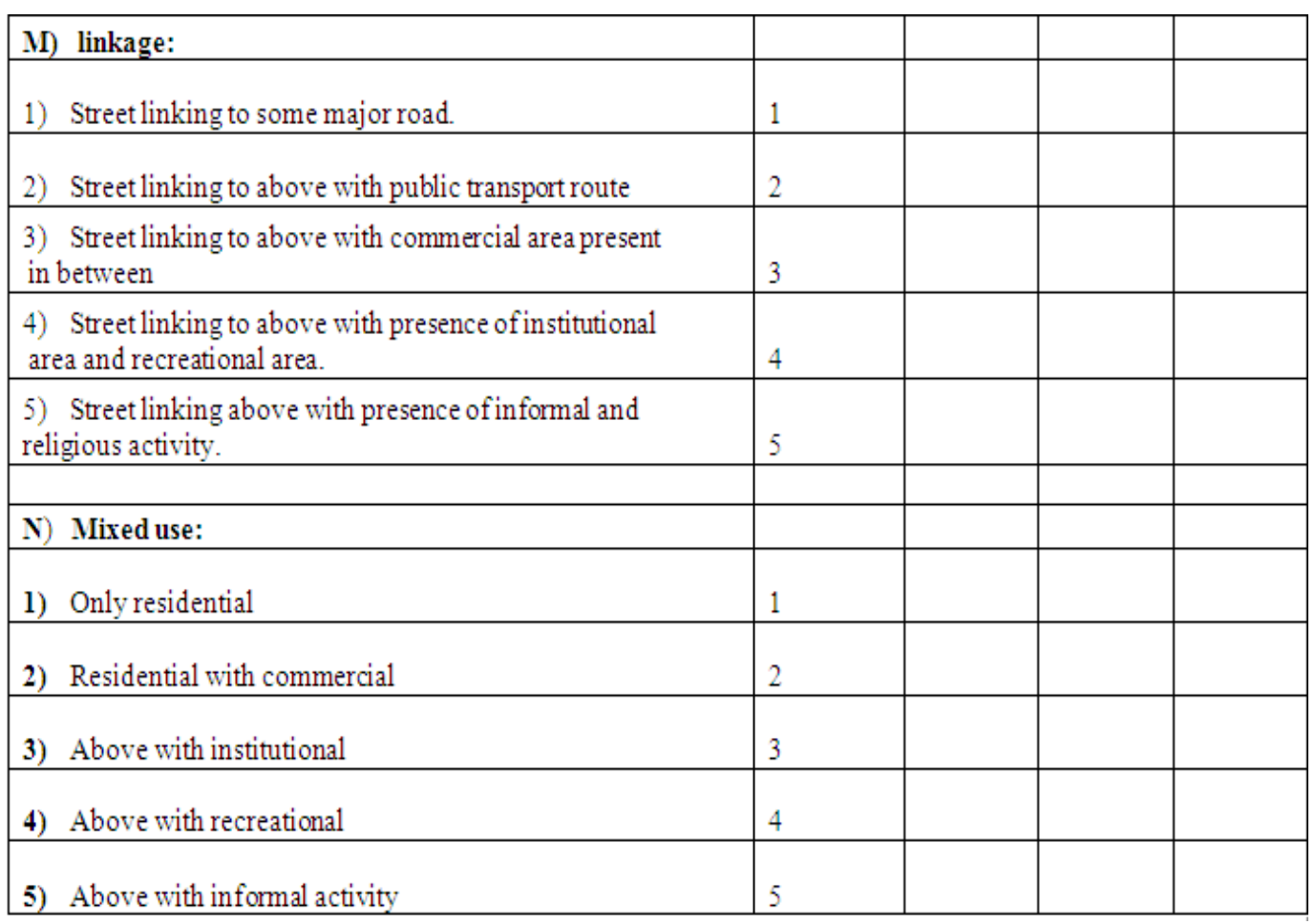




\section{CONCLUSION}

Enhancing walkability in a neighborhood is an initial step and important part in creating the society more sustainable. A tool can be derived which can calculate the walkability of the street and after that those street which did got much marks in the matrix will became the first priority designing and converting to more walkable streets. The matrix can help the developer in judging and analyzing the neighborhood. Converting all the parameters into an either it is quantitative or qualitative can help to analysis the street without any discrimination and favourism. Quantitative analysis also reduces the subjectiveness of the parameters.

\section{REFERENCES}

1. Alexander, C., 1977. A pattern language: towns, buildings, construction. New York: Oxford University Press.

2. Alexander, C., 1965. A city is not a tree, Architectural Forum.

3. Chin, G.K., et al., 2007. Accessibility and connectivity in physical activity studies: the impact of missing pedestrian data, Preventive Medicine.

4. Gehl, J., 1987, Life between buildings. New York, NY: Van Nostrand-Reinhold.

5. Cullen, G., 1961, The concise townscape. New York, NY: Reinhold.

6. Hillier B, and Hanson, J., 1984, The social logic of space, Cambridge University Press.

7. Hillier B., 1996. Space is the machine: a configurational theory of architecture, Cambridge University Press.

8. Jacobs, A. B. (1993), Great streets. Cambridge, MA: MIT Press.

9. Jacobs, J. The Death and Life of Great American Cities: The Failure of Town Planning, Harmondsworth, Middlesex, Penguin, 1964 (first published 1961)

10. Lang, J., 1987. Creating architectural theory: the role of the behavioral sciences in environmental

11. design. New York, NY: Van Nostrand-Reinhold.

12. Lynch, Kevin, The Image of the City, Cambridge, Mass., The MIT Press, 1960

13. Newman, O. 1972 Defensible space. New York: Macmillan.

14. Rapoport, A. 1977, Human aspects of urban form. Oxford: Pergamon.

15. Rossi, A., 1982, The architecture of the city. Cambridge, MA: MIT Press.

16. Trancik, R., 1986. Finding lost space: theories of urban design. New York: Van Nostrand Reinhold.

17. Whyte, W.H., 1980, The social life of small urban spaces. Washington, DC: The Conservation Foundation.

\section{Author Introduction}

Ar. Divya Pandey is an Architect currently working in Faculty of Architecture at Dr. A.P.J. Abdul Kalam University, Lucknow, Uttar Pradesh as an Assistant Professor. She has done his Masters from SPA Bhopal, and currently pursuing Post Graduation Diploma in Environmental and Sustainable Development.

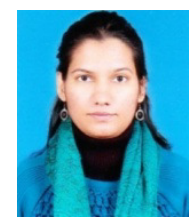

